\title{
A Small Planar Log-Periodic Koch-Dipole Antenna (LPKDA)
}

\author{
Dimitrios E. Anagnostou*(1), John Papapolymerou ${ }^{(1)}$, \\ Christos G. Christodoulou ${ }^{(2)}$ and Manos Tentzeris ${ }^{(1)}$
}

(1) Georgia Institute of Technology, ECE Department, Atlanta, GA, 30308, USA (2) University of New Mexico, ECE Department, Albuquerque, NM, 87106, USA

\begin{abstract}
Koch dipole elements are introduced in a planar log-periodic dipole antenna array, in order to minimize its size. The advantages and disadvantages of the proposed LPKDA array are presented and discussed with an emphasis on the minimization characteristics of the design.
\end{abstract}

Index Terms -Antennas, Array, Fractal, Koch, Log-periodic

\section{INTRODUCTION}

Log-periodic dipole antenna (LPDAs) arrays used in radio signal detection applications have been constructed so far using Euclidean radiating elements and have achieved high directivity and low cross-polarization ratio over a very wide frequency range. In applications where space constraints restrict the use of full-sized elements, alternative smaller designs need to be considered. In this work, Koch fractal dipoles are introduced as the basic structural elements of a planar Log-Periodic Koch-Dipole Antenna (LPKDA) array, thus replacing the full-sized Euclidean monopoles. Design considerations are presented herein and the performance characteristics of the proposed antenna are discussed.

\section{LPKDA ANTENNA DESIGN}

The primary goal in this work is the proof of concept of a log-periodic Koch-dipole antenna (LPKDA) array design. This antenna will be used to cover the $2-3 \mathrm{GHz}$ frequency range. For a Euclidean log-periodic dipole antenna (LPDA) array, the largest element's dimensions can be determined by the lowest desired frequency of operation. The antenna is fabricated on $\mathrm{t}=1.588 \mathrm{~mm}$ thick FR-4 substrate with relative permittivity of $\varepsilon_{\mathrm{r}}=5$. Initially, matched single-element designs for Euclidean and Kochshaped monopoles at the low frequency end were studied and their characteristics are summarized in Table I. It can be seen that a $28.4 \mathrm{~mm}$ long Euclidean element resonates at $1.82 \mathrm{GHz}$ while the vertical length of a Koch element can be only $25.6 \mathrm{~mm}$. The percent vertical-size reduction with respect to the Euclidean element is: $\frac{\text { Length }_{\text {Eucl.Vert. }}-\text { Length }_{\text {Koch.Vert. }}}{\text { Length }_{\text {Eucl.Vert. }}}=9.9 \%$. Also, the percent reduction in the vertical length of the Koch element with respect to its own total length is given by: 
$\frac{\text { Length }_{\text {Koch.Total. }}-\text { Length }_{\text {Koch.Vert. }}}{\text { Length }_{\text {Koch.Total. }}}=15.5 \%$. All other elements are sized proportionally using the method described in [1], and by taking into consideration the desired theoretical performance of the antenna using the corrected Carrel's tables [2,3]. The spacing factor used in this case is given by: $\sigma=\frac{1-\tau}{4 \tan \alpha}=\frac{d_{n}}{4 h_{n}}=0.076$, where $\tau$ is the scaling factor $\tau=\frac{L_{n}}{L_{n+1}}=\frac{r_{n}}{r_{n+1}}=0.85$ and $\alpha$ is the structure's half-angle $\alpha=26^{\circ}$, as defined in Fig. 1 .

\section{LPKDA ANTENNA RESULTS}

The LPKDA array's reflection coefficient is compared to the Euclidean LPDA's in Fig.2 (a, b). A frequency range between $1.75 \mathrm{GHz}$ and $3 \mathrm{GHz}$ is covered, while the LPKDA array maintains its directive and similar radiation patterns over the entire bandwidth as shown in Fig. 3. In Fig. 4, the gain and directivity of the LPKDA are also shown.

Table I.

\begin{tabular}{|c|c|c|c|c|c|c|c|}
\hline \multicolumn{8}{|c|}{ Resonant Performance (1-element) } \\
\hline \multirow{2}{*}{$\begin{array}{c}\text { Antenna } \\
\text { Type }\end{array}$} & \multirow{2}{*}{$\begin{array}{c}\text { Resonant } \\
\text { freq. }\end{array}$} & \multirow{2}{*}{$\begin{array}{c}\text { Total } \\
\text { Length }\end{array}$} & \multirow{2}{*}{$\begin{array}{l}\text { Vertical } \\
\text { Length }\end{array}$} & \multirow[t]{2}{*}{$\mathbf{Z}_{\text {in }}$} & \multirow[t]{2}{*}{$\% \mathrm{BW}$} & \multicolumn{2}{|c|}{ \% Miniaturization } \\
\hline & & & & & & Vertical Length of & Vertical \\
\hline Eucl. & $1.76 \mathrm{GHz}$ & $29.4 \mathrm{~mm}$ & $29.4 \mathrm{~mm}$ & $49.0 \Omega$ & $13.0 \%$ & Euclidean and & Ler \\
\hline Eucl. & $1.82 \mathrm{GHz}$ & $28.4 \mathrm{~mm}$ & $28.4 \mathrm{~mm}$ & $49.0 \Omega$ & $13.0 \%$ & Koch elements & Koch elem \\
\hline Koch & $1.82 \mathrm{GHz}$ & $30.3 \mathrm{~mm}$ & $25.6 \mathrm{~mm}$ & $44.4 \Omega$ & $12.6 \%$ & $9.9 \%$ & $15.5 \%$ \\
\hline
\end{tabular}

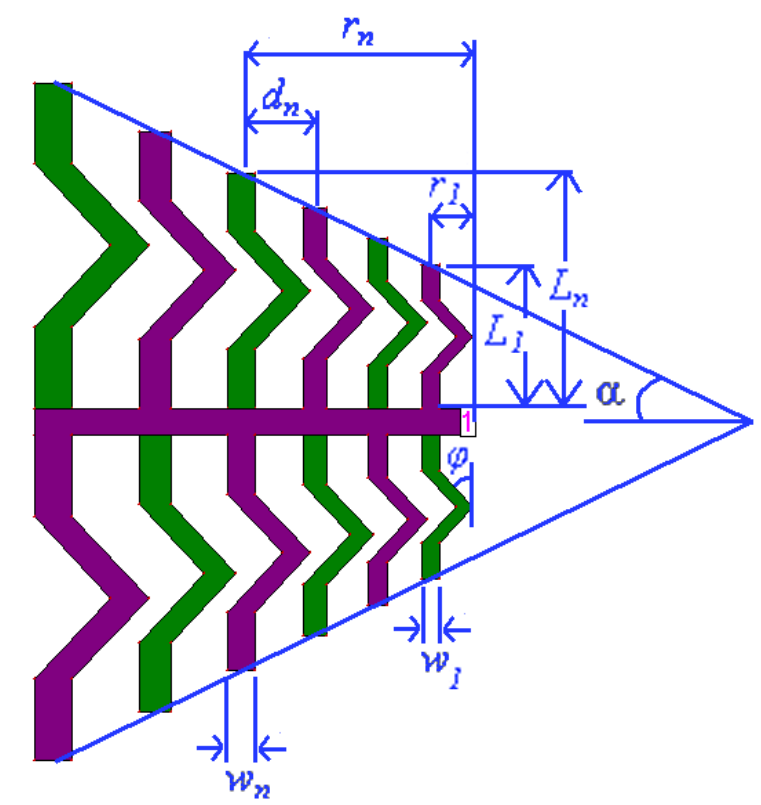

Fig. 1. Design characteristics of the Koch Log-Periodic Dipole Array Antenna. 
A comparison of the results shows that both designs exhibit very similar characteristics. Both antennas have the same frequency range covered with a reflection coefficient magnitude of $\left|S_{11}\right|<-10 \mathrm{~dB}$, while the LPKDA array has a constant gain of $\sim 3.2 \mathrm{dBi}$, only $0.3 \mathrm{dBi}$ less than the simulated Euclidean design. The results are also consistent with the theoretical expected values of directivity published in [2,3]. Most importantly, the LPKDA achieves a $\sim 6 \mathrm{dBi}$ directivity, only $0.5 \mathrm{dBi}$ less than the simulated antenna, using $11 \%$ less space, which relates to a significant reduction in the weight and the occupied by the antenna structure. The total area of the LPKDA is only $1323 \mathrm{~mm}^{2}$ while the Euclidean design's total surface is $1505 \mathrm{~mm}^{2}$. Cross-polarization results for the proposed design are also very low. Cross-polarized radiation in the $\varphi=0^{\circ}$ plane remain unchanged, while in the $\varphi=90^{\circ}$ plane it did not exceed $-22 \mathrm{dBi}$.

\section{CONCLUSIONS}

A new planar log-periodic dipole antenna design was presented with the introduction of Koch-shaped dipole elements in replacement of the conventional and widely-used Euclidean elements. Advantages and disadvantages of the proposed LPKDA array were presented and discussed. The designed antenna can cover the same frequency band, with constant gain, similar radiation patterns and with a comparable to a conventional LPDA performance. In addition the proposed antenna has smaller size by $11 \%$, which results in less weight and additional free and useable space.
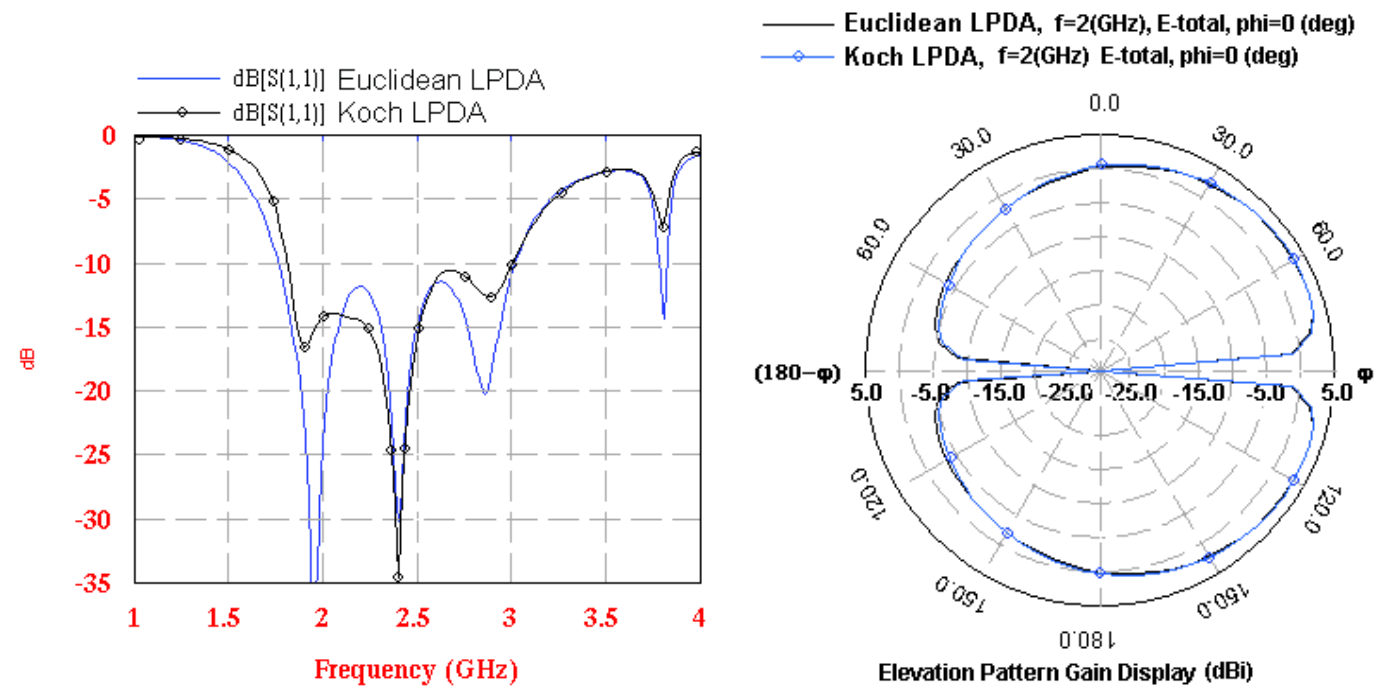

Fig 2. a) Reflection coefficient and b) radiation patterns comparison between the Euclidean and the Koch-element LPDA. 


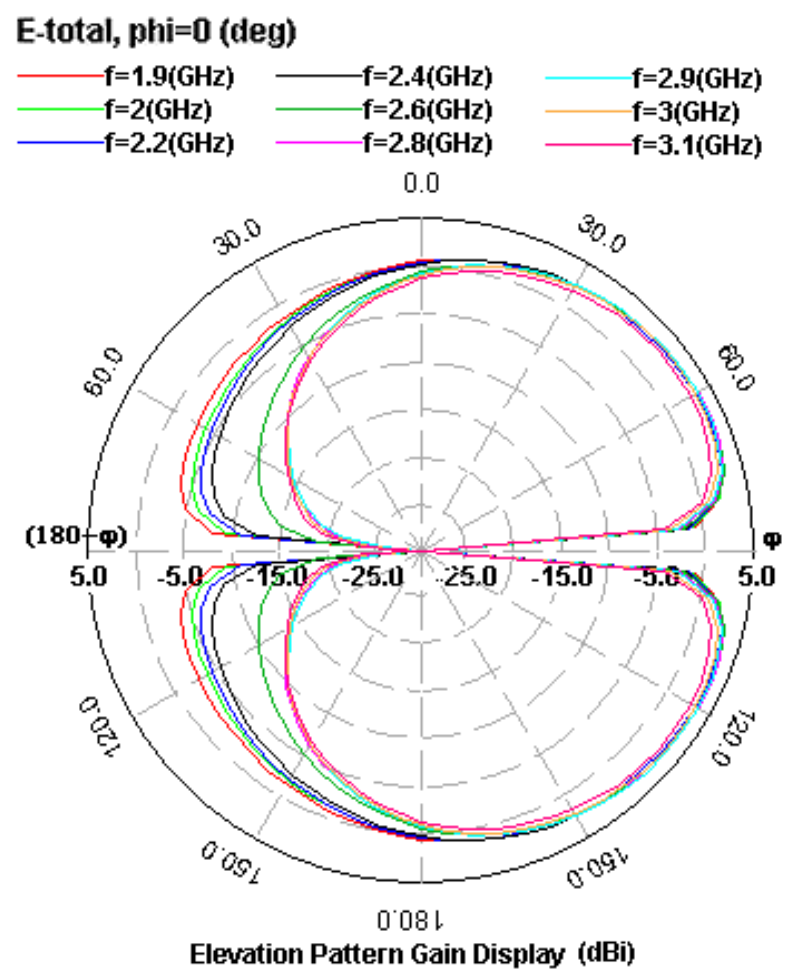

Fig. 3. Radiation patterns of the LPKDA antenna over its entire bandwidth.

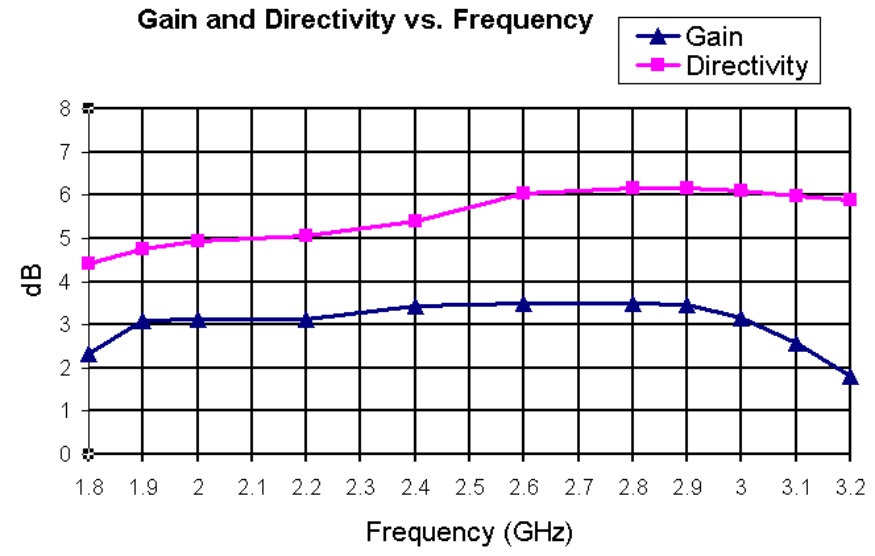

Fig. 4. Gain and directivity of the LPKDA over frequency.

\section{REFERENCES}

[1] Campbell C. K., Traboulay I., Suthers M. S. and Kneve H., "Design of a Stripline Log-periodic Dipole Antenna", IEEE Transactions on Antennas and Propagation, Vol. 25, Issue 5, Sept. 1977, pp. $718-721$.

[2] Carrel R. L "The Design of Log Periodic Dipole Antenna", IRE International Convention Rec., 1961, pt. 1, pp. 61-75.

[3] Butson P. C. and Thompson G. T., "A Note on the Calculation of the Gain of LogPeriodic Dipole Antennas", IEEE Transactions on Antennas and Propagation, Vol. 24, Issue 1, Jan. 1976, pp. 105-106. 